\title{
A concept of materialism and well-being
}

\author{
Asa Ismia Bunga Aisyahrani ${ }^{1}$, Lina Handayani ${ }^{2}$, Maya Kusuma Dewi ${ }^{3}$, Mastura Muhtar ${ }^{4}$ \\ ${ }^{1,4}$ Faculty of Social Sciences and Humanities, Universiti Teknologi Malaysia, Malaysia \\ ${ }^{2,3}$ Faculty of Public Health, Universitas Ahmad Dahlan, Indonesia
}

\begin{tabular}{l}
\hline \hline Article Info \\
\hline Article history: \\
Received Dec 3, 2019 \\
Revised Feb 10, 2020 \\
Accepted Feb 29, 2020 \\
\hline
\end{tabular}

\section{Keywords:}

Corruption

Financial

Materialism

Social

Welfare of life

\begin{abstract}
Materialism is related to financial individuals who judge all things need material. The nature of people like this exist in today's era, which assesses a success comes from the acquisition of wealth, social status and welfare of life. Although this is contrary to moral life, there are still many people who pursue it. Internal and external factors exist in human life related to the existence of materialism. Self satisfaction and individual life goals are internal factors that exist within the individual. Materialistic people will feel satisfied through acquisition of possessions, financial success, attaining status and having the right image. This perception is negatively correlated with well-being, even so they believe that their life goals will be achieved through materialism. Environmental, social and social media influences that are external factors in an individual can provide a tendency to influence one's behavior. The recognition of social status based on wealth will have an impact on materialism that will be difficult to escape from his life. The hedonist lifestyle and corruption are the effects of this growing materialism. However, to prevent or overcome these behavioral problems, it is necessary to strengthen morality and spiritual values that can be obtained from various sources such as the Qur'an, the Bible or research that can be trusted to provide solutions to these problems.
\end{abstract}

This is an open access article under the CC BY-SA license.

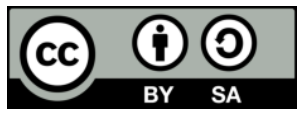

\section{Corresponding Author:}

Lina Handayani,

Faculty of Public Health, Universitas Ahmad Dahlan,

Prof. DR. Soepomo Sh Street, Umbulharjo, Yogyakarta City, Daerah Istimewa Yogyakarta, Indonesia 55164.

Email: linafkm@gmail.com

\section{INTRODUCTION}

Materialism has been discussed among philosophers and researchers since years ago. It has become a very influential topic in human life. There are many explanations in understanding materialism. A researcher Watson said the meaning of materialism is the belief that the central goals of life are the acquisition of possessions, financial success, attaining status and having the right image [1]. Jerome et al also has explained that Materialistic people perceived materialism as necessary for life success and happiness, in which personal value system in the acquisition and possession of material (consumer) goods is assumed as central to the self [2].

Individual differences including affective, cognitive and behavioral oucomes in perceiving the important of material values has been assumed as a predictor of subjective well-being [3]. These materialistic people think that success is judged by the things individual possesses, while actually materialism has negative correlation with subjective well-being [4]. The main point of this article is the relation between materialism and well-being is bidirectional and the path from ill-being to materialism 
seems stronger [5]. Philosophers and theologians have been complaining for long about the impacts of materialism in human life. Accordingly, this article provides three subheadings regarding to the topic.

For the beginning, there will be explanations and discussions about the factors of the existence of materialism. A recent meta-analysis by Dittmar et al [5] shows that higher levels of materialism are associated with lower levels of well-being. Research by Kasser and Ryan demonstrates that extrinsic goals are associated with lower level of well-being, whereas intrinsic goals are associated with higher level of wellbeing [5]. And empirical evidences also prove that outcomes such as life satisfaction, happiness, vitality, and self-actualization will be scored lower if people more prioritized values and goals for money and possessions in life [6]. Nevertheless, many people are still pursuing material aspects. Therefore, what is the reasonable reasons so that they keep persistently on materialism? Why do not they look for other ways to achieve the highest values in life? These questions will be discussed as follows.

Secondly, the behaviours related to materialism and the impacts of materialism on individual and social behaviour will be discussed together with the examples. Many negative behaviours that caused by materialism exist nowadays, such as impulsive buying, flexing, hedonist lifestyle and so on which are very common in the society recently. It also has been proven that materialism had a negative effect upon mental health at low and medium levels [1]. Accordingly, the discussion in this subheading is about how that negative behaviours can arise and what is the influence of materialism to the welfare of life.

The last subheading is about the solutions regarding to correlation between the highest values in life with aspects of materialism. Scientific experiment results indicate that greater explicit materialism is associated with less well-being and more symptoms of depression [7]. Despite of that, the importance of morality and spiritual values needs to be emphasized to either prevent or overcome behavioral problems. Many sources such as from The Qur'an, The Bible or even research can be trusted as a guide to give many solutions regarding to the problems.

\section{RESEARCH METHOD}

This paper is based on literature review. Online literature searches were conducted in Science Direct, the Journal of Business Research, and the Journal of Consumer Psychology. Strategies in the search include the following keywords: corruption, financial, materialism, social and welfare of life. Search in English, but there is no limit to the year of publication.

\section{RESULTS AND DISCUSSION}

\subsection{The factors of the existance of materialism}

Materialism is typically defined as the pursuit of status and happiness through the acquisition of wealth and material possessions [5]. There are branches of factors that bring the existance of materialism into human life, and the outline factors can be defined as internal and external factors.

\subsubsection{Internal factors}

Internal factors is when people infer that person's behavior is due to personal factors such as traits, abilities, or feelings [8]. Personality will affect one's well-being, this is related to the ability to move [9]. Things inside human being beyond the eyes can see that empower someone's behaviour to be materialistic can be assumed as internal factors. These are the outline:

\section{a. Self satisfaction}

Materialistic people hardly treat others as their equals and often go further to show off their wealth. They hardly care about anyone but themselves and frequently tend to exploit and trample people through inappropriate ways. This belief is based on individuals internal. For them, happiness of life is by achieving self satisfaction. The formulas towards self satisfaction are materialism as the basic thing, enhancement values and individual competitiveness as the mediator, and self satisfaction as the core purpose. The formula refere to the conceptual model presented in Figure 1. That conceptual model indicates that as one's level of materialism increases by one unit, their satisfaction decreases [10]. Social stratum obtained will produce something interesting on individual satisfaction and psychological well-being [11].

In addition, "High quality, expensive, and non-essential products and services that appear to be rare, exclusive, prestigious, and authentic offer high levels of symbolic and emotional/hedonic values" [12]. Nowadays, people can quickly and easily access every worth things they want through social media, it includes product review and information. The advertisement that appears is also very fascinating. This convenience and satisfaction are very potential to bring high tendency of materialism in life. 


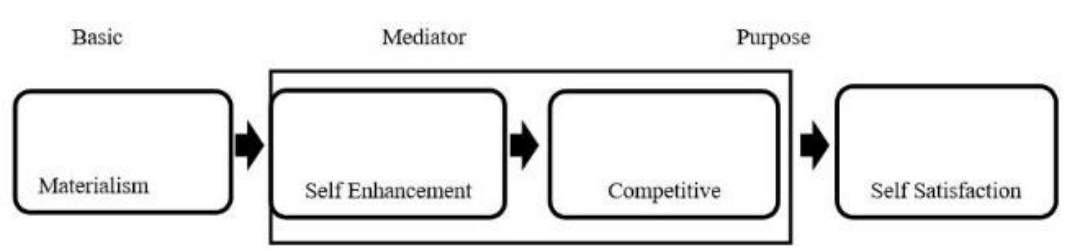

Figure 1. Conceptual of self satisfaction

\section{b. Purposes of life}

People tend to engage with activities that support their important values, as such those with stronger materialistic values and goals are more likely to engage with materialistic activities such as buying things, whereas those with stronger environmental values will be more likely to engage in pro-environmental activities [13].

There are some values and goals that materialistic people tightly hang on them. The purposes conflict with morality and the well-being of life, but they strongly believe that their purposes of life seem to be attainable through materialism.

1) Self-enhancement values

This purpose includes social power which means able to control over others, dominance or able to defeat others, wealth or can be explained as pursuing material possessions and money, authority to lead or command, and influence or having an impact on people and events.

2) Materialism success

Success here interpreted as reliability of acquiring material possessions, pursuing others admiration and recognition as the most important achievements in life. The more admiration and recognition of wealth from others, it seems increasingly close to the top of success.

3) Materialism centrality

This is about giving more emphasis on material things above the existence of other things. Material is positioned as the principal thing to be maintained, while other things can still be ruled out. The main thing is self-esteem should always be maintained through material existence.

4) Materialism happiness

The perspective is about generalizing all happiness by pursuing all of the things that has not been owned yet, or it more like always feeling dissatisfied. Because desire to gain of all the things that wanted is such an impossible thing.

5) Competitiveness

Competition between people leads to more progress than cooperation does. The competition is performed to benefits everyone in the end [10]. Therefore, benefits is the goal and the competition is just a way to win the goal, wealth is the goal and competing in materialistic lifestyle as the medium.

\subsubsection{External factors}

External factors can be assumed as the influences that do not occur from within the individual but from elsewhere like environment, social influence and social media. Both factors can be observed easily throughout surroundings, its characteristics are also very visible.

\section{a. Environment}

Some theories show that environment has a high tendency to influence someone's behaviour. Such as theory of classical conditioning, this theory states that behavior is result of continuing exposure to specific environmental factors [14]. When the environment has a high authority in life, many people are disable to maintain their behaviour wisely.

For example, there is an immigrant resident lives in the capital city. Environmental lifestyle of capital city is quite different than the environmental lifestyle in his hometown. People who live in capital city or can be called as modern societies mostly like to pursue materialistic trends as their lifestyle, such as buying branded items and spending time at shoping centers [2], while in the countyside it is not a trend. At the beginning he still survive with his normal lifestyle, but his behavior changes gradually at the same time he observe many people seem very satisfied with materialistic lifestyle. Accordingly, materialistic lifestyle is no longer become a weird lifestyle on his perspective.

It can be related with Ivan Pavlov's experiment of classical conditioning [14], which materialistic lifestyle can be defined as neutral stimulus that will turn lastly into conditioned stimulus, people satisfaction 
as unconditioned stimulus and the change of immigrant resident's behaviour as unconditioned response, that will turn lastly into conditioned response after conditioning.

\section{b. Social influence}

Social influence is the process by which the actions of an individual or group affect the behaviour of others [15]. Sociality play a central role in our lives, it has own norms, beliefs, expectation and standars about what is worthy for sociality members. Sociality also emphasizes considerable social pressure over individuals, does not fulfill social criterias should bring on being ignored aven rejected or exclude by the sociality. This is what forces everyone to enroll with life mainstream. People who support materialistic values are people who care about social desires [16].

A change in behaviour or attitudes brought about by a desire to follow the beliefs or standards of other people is called by conformity [15]. It can be explained simply as "Following what others do". For example, a foreigner student comes to New York for joining student mobility program, which uses western lifestyle or hedonism as the medium of sociality. Day by day, time keeps running and he feel like he has to adjust himself with the sociality if he want to make friends, enjoy the environment and of course to survive in this new country. So, after few months gradually he changed his lifestyle with similar lifestyle as the natives. Equal to materialism, when the surroundings is more dominant to materialistic lifestyle, almost recidents will be affected to be materialistic to maintain their self-esteem.

\section{c. Social media}

Almost everyone is very dependent on social media, from children even elderly parents can access it easily nowadays. It can even be said that people can live without eating, drinking or sleeping, but not without social media. Life becomes more practical through social media; people can find a lot of information about anything they want to know and of course it brings a high tendency to be influenced by social media waves. Social media provides marketers with an expansive set of tools that enable them to reach consumers directly [12]. Consequently, the tendency to buy and buy increases significantly.

The overview of social media influence can be shown by Para-Social Interaction (PSI). It explains the relationship between media personalities and media users, about "interpersonal involvement of the media user with what he or she consumes", this involvement includes "seeking guidance from a media persona, seeing media personalities as friends, imagining being part of a favorite program's social world, and desiring to meet media performers." [12]. For example, individuals are likely to compare ownself with the common values, they have high expectation to be similar to what or who they idolize, and conformity motives are shown clearly [17]. Related to that, purchase intentions significanly increased in order to fulfill the needs.

Research also has illuminated relationships between materialism and constructs such as self-presentational tendencies and types social media used. Social media use becomes "problematic" when it causes distress to users, including impaired social, emotional functioning, and lower subjective well-being [17]. Some of the most consistent findings regarding materialism are its negative relationships to psychological health, life satisfaction, and other well-being measures [18]. It proves that social media plays a significant role towards self-presentational tendencies to materialism.

\section{THE BEHAVIOURS RELATED TO MATERIALISM AND THE IMPACTS OF MATERIALISM}

Values or goal orientations and overt behaviours influence each other in a mutually reinforcing manner. On the one hand people tend to engage with activities that support their important values [13]. If someone establish that the important values of his life is the recognition of high social status based on wealth, then higher levels of materialism and lower levels of well-being will be difficult to escape from his life. The materialism model can improve the welfare and quality of life of individuals [19]. These are some of the behaviors that are strongly related to materialism:

\subsection{Impulsive buying}

"Appearances have become more important than substance. They buy a car not because it could bring them from one place to another but to make them feel better. It is about our value system. One example is buying a Honda City when they can only afford a Perodua Kancil," said Datuk Paul Selvaraj, Chief Executive Officer of Federation of Malaysian Consumers Associations (Fomca) [20]. This case occurs that materialistic society pursue to pay a high price for choosing status over their needs. While the basic rule of smart consumerism was spending within one's means and being mindful of consumption. People's behavior has changed from what it should because of materialism. 


\subsection{Flexing}

Flexing is when people show off the stuff they got [21]. Usually it happens through Instagram, YouTube and Facebook. People want to prove they have made it to the top. They want to exhibit their strengths and accomplishments. Others show off "to arouse jealousy, envy, or other negative emotions" in others. They create Instagram Envy to prove that they can't be overshadowed. And some people believe that showing off their money will bring them more friends and fans [22].

Traffic from subscribers and anonymous viewers increases significantly when YouTube vloggers upload videos about products they use or their personal life. Thereby vloggers become what is known as YouTube celebrities. It has strong potential to influence consumer perceptions of luxury brand products [23]. Again, about the ego to be seen as luxurious, everyone seems race to show off their wealth and forget about the more important life goals.

\subsection{Hedonist lifestyle}

Hedonism today refers to a way of life where experience of pleasure is paramount, especially as part of modern consumerism rather than artistic or aesthetic fulfillment [24]. In broad terms, a hedonist is someone who tries to maximise pleasure and minimise pain [25]. But often materialistic pleasure tends to become uncontrollable hunger, it is no longer a motivation nor relief. It also has been proven that materialism had a negative effect upon mental health at low and medium levels [1]. Materialism and hedonism have wiped the pleasure away by its contrary to aesthetic fulfillment. Because hedonist lifestyle emphasizes to be more, bigger, even better and best. While a harmonious life is without the pursuit of riches or glory.

\subsection{Corruption}

Based on Government Transformation Programme 1.0 in fighting corruption, RM 10 billion per year or 1 to 2 percent of gross domestic product per year must be borne by Malayisa due to corruption activities [6]. The desire to have more material in an easy way has stated corruption as an effective shortcut. Materialistic people use every available means to ensure that the rest of the people in the society remain poor. The aspect of materialism is leaders are driven by greed and embezzling public funds is to maintain their status. Therefore, corruption does not always mean cash, but it can also in the form of votes, services, positions or work placements, and all other forms of payment and purchase [6].

Inequality causes corruption, moreover that corruption does not produce per se income inequality. Using a panel of 50 countries during the period 1995 through 2015, with a two-step Arellano-Bond dynamic GMM estimation, it shows that increases in income inequality are responsible for increasing corruption. The reasons why inequality is the responsible for increasing corruption are several, and the main is that when poverty is widespread and people underpaid, the incentives to pursue wealth (even in an unfair and illegal way) increase [26].

\section{THE SOLUTIONS REGARDING TO CORRELATION BETWEEN THE HIGHEST VALUES IN LIFE WITH ASPECTS OF MATERIALISM}

\subsection{Spiritual perspective}

\subsubsection{Islamic perspective}

Life is unexplicit word to be desribed, and it has no meaning without obvious purposes, "The purpose of life is a life of purpose" [27]. The Qur'an as The Muslims Sacred Book gives a lot of guidances about the highest value in life, includes life purposes, ultimate happiness and so on. Surah Al-Qashas verse 49-50 for example, this verse dictate Muslims to follow the right foundation of life and it also explain about.

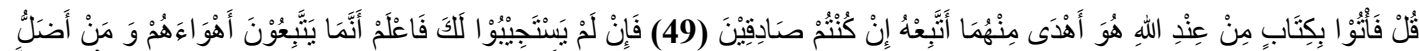

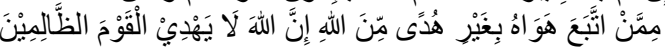

"Say: Then bring a Book from Allah, which is better guide than either of them, that I may follow it! (do), if you are truthful (49) But if they hearken not to thee, know that they only follow their own lusts: and who is more astray than one who follow his own lusts, devoid of guidance from Allah? For Allah guides not people given to wrong doing" (50) [28].

Indeed, materialism arises from human lusts. Following own lusts tends toward badness because humans will never be satisfied. People affected by materialism are actually unhappy, even if they achieve happiness in momentary. Because their happiness is caused by physical things such as I-phone, cars, superbikes etc. While the one who really understands the happiness will know that visiting mother after a long time is actual happiness for example [29]. Although lusts will always appear throughout the lifespan, 
but it still can be reduced by emphasizing the fear of God's wrath towards ourselves and realizing the welfare and blessings of God as the highest values in life.

\subsubsection{Christian Perspective}

In one agreement that materialism is not the central of happiness or even the highest value in life, The Bible also gives injunctions: Jeremiah 9:23 "Thus says the Lord: Let not the wise man boast in his wisdom, let not the mighty man boast in his might, let not the rich man boast in his riches". Boasting in possessions is not justified in the Bible, then what needs to be done is mentioned in this verse: Peter 3:3 "Don't be concerned about the outward beauty of fancy hairstyles, expensive jewelry, or beautiful clothes. You should clothe yourselves instead with the beauty that comes from within, the unfading beauty of a gentle and quiet spirit, which is so precious to God". Therefore, humans have to understand deeply that the beauty that comes from within is more valuable than the material aspects, because eternal happiness lies there [30].

\subsection{Rational Perspective}

Some researchers [7] has done an experiment about the correlation between materialism and wellbeing. The results indicate that greater explicit materialism is associated with less well-being and more symptoms of depression. In materialistic people, objects would present a greater importance for emotional state, while in eudaimonic people, actions would be strongly associated with emotional state [7]. Many negative impacts rise upon the materialism, therefore these complications should be overcome properly.

Beside by realizing the highest values in life, "Terror management theory (TMT)" has been identified as a possible antecedent of materialism. People often seek out mechanism of enhancing their selfesteem when reminded of their own mortality [31]. Death signals a separation from worldly possessions that may be particularly disturbing to materialistic individuals [18]. Following a brief overview of TMT evidence is reviewed that explicates how intimations of mortality increase materialism as a way to enhance self-esteem and affects consumer decisions that support one's cultural worldview [32]. Consequently, the fear of death becomes a powerful brake to hold back materialism.

In easy words, materialism is a view of life that comes from the self and is influenced by the surroundings, so the greatest power to overcome this case must come from within. The proverb says "I do not believe that you should devote overly much effort to correcting your weaknesses. Rather, I believe that the highest success in living and the deepest emotional satisfaction comes from building and using your signature strengths. "[33].

Sustainable lifestyles are characterised by less materialism, higher environmental values and higher well-being [10]. Materialistic society pursue to pay a high price for choosing status over their needs. They jump across their afford and let negative influences affect them. Such as having unbalanced life, plunged into hedonist lifestyle, pursuing impulsive buying and so on. The relation between materialism and well-being is bidirectional and the path from ill-being to materialism seems stronger [5].

\section{CONCLUSION}

People's behavior has changed from what it should because of materialism. People affected by materialism are actually unhappy, even if they achieve happiness in momentary. Because their happiness is not eternal, while the welfare and blessings of God is the highest values in life and the ultimate happiness.

High levels of material values are negatively associated with subjective well-being, psychological and contextual variables. Then if someone establish that the important values of his life is the recognition of high social status based on wealth, then higher levels of materialism and lower levels of well-being will be difficult to escape from his life.

In conclusion, people have to build strong foundation in their understanding about the highest values in life, the true purposes in life, and the way of filtering influences from surroundings. Even though rational perspective such as from research or spiritual perspective such from The Qur'an and other Sacred Books have given such great solutions, but the greatest power in preventing materialism and balancing well-being still must come from within.

\section{REFERENCES}

[1] Watson, D. C. "Materialism: Temporal balance, mindfulness and savoring," Personality and Individual Differences, vol. 146, pp. 93-98, 2019. 
[2] Cavazos-arroyo J., "Influence of gratitude and materialism on two different conceptualizations of subjective wellbeing *," Universitas Psychologica, vol. 18, no. 3, 2019.

[3] Jiang Jiang, Yue Song, Yannan Ke, Rong Wang \& Hongyun Liu, "Is disciplinary culture a moderator between materialism and subjective well-being? A three-wave longitudinal study," Journal of Happiness Studies, vol. 17, pp. 1391-408, 2016.

[4] Kasser T, Rosenblum KL, Sameroff AJ, Deci EL, Dittmar H, Dungan N, et al. "Changes in materialism, changes in psychological well-being: Evidence from three longitudinal studies and an intervention experiment," Motivation and Emotion, vol. 38, pp. 1-22, 2014.

[5] Pandelaere, M. "Materialism and well-being: The role of consumption," Current Opinion in Psychology, vol. 10, pp. 33-38, 2016.

[6] Kapeli NS, Mohamed N. "Insight of anti-corruption initiatives in Malaysia," Procedia Econ Financ., vol. 31, no. 15, pp. 525-34, 2015.

[7] Muñiz-Velázquez, J. A., Gomez-Baya, D., \& Lopez-Casquete, M. "Implicit and explicit assessment of materialism: Associations with happiness and depression," Personality and Individual Differences, vol. 116, pp. 123-132, 2017.

[8] Notes, S. "SparkNotes: Social Psychology: Attribution," Retrieved from https://www.sparknotes.com/psychology/psych101/socialpsychology/section3/,2017.

[9] Anand P, Hunter G, Ron S. "Capabilities and Well-being: Evidence based on the sen-nussbaum approach to welfare," Harbin Gongye Daxue Xuebao/Journal of Harbin Institute of Technology, vol. 39, no. 11, pp. 1710-4, 2007.

[10] Thyro A, Kilbourne WE., "Self-enhancement and individual competitiveness as mediators in the materialism/consumer satisfaction relationship," Journal of Business Research, vol. 92, pp. 189-196, 2018.

[11] Wright ND, Larsen V., "Materialism and life satisfaction: A meta-analysis," Journal of Consumer Satisfaction, Dissatisfaction, and Complaining Behavior, vol. 6, pp. 158-165, Jan 1993.

[12] Lee JE, Watkins B., "YouTube vloggers' influence on consumer luxury brand perceptions and intentions," Journal of Business Research, vol. 69, no. 12, pp. 5753-60, 2016.

[13] Gatersleben B, Jackson T, Meadows J, Soto E, Yan YL, "Leisure, materialism, well-being and the environment," Revue europeenne de psychologie appliquee, vol. 68, no. 3, pp. 131-1399, 2018.

[14] Feldman, R. Development Across the Life Span. Edinburg: Pearson Education, 2018.

[15] Feldman, R. Psychology and your life with P.O.W.E.R learning, 4th ed. New York: Mc Graw Hill Education, 2016.

[16] Vargas PT, Yoon S., "On the psychology of materialism: Wanting things, having things, and being happy. advertising \&amp, Society Review, vol. 7, no. 1, 2006.

[17] Marino C, Gini G, Angelini F, Vieno A, Spada MM., "Social norms and e-motions in problematic social media use among adolescents," Addict Behav Reports, [Online] Available: https://doi.org/10.1016/j.abrep.2020.100250, 2020.

[18] Christopher AN, Drummond K, Jones JR, Marek P, Therriault KM, "Beliefs about one's own death, personal insecurity, and materialism," Personality and Individual Differences, vol. 40, no. 3, pp. 441-451, 2006.

[19] Shrum LJ, Lowrey TM, Pandelaere M, Ayalla A., "Materialism: the good , the bad , and the ugly," Journal of Marketing Management, vol. 30, no. 17, 2014

[20] Rahim, R. "Materialistic society paying a high price for choosing status over their needs," Retrieved from: https://www.thestar.com.my/news/nation/2011/09/26/materialistic-society-paying-a-high-price-for-choosing-statusover-their-needs/, 2011.

[21] Dboii, "Urban Dictionary: Flexin," Retrieved from: https://www.urbandictionary.com/define.php?term=Flexin, 2010.

[22] Bennett, T. "Social media culture: Flexing on the gram - get kids internet safe," Retrieved from: https://getkidsinternetsafe.com/flexing/22019.

[23] Tobacyk JJ, Babin BJ, Attaway JS, Socha S, Shows D, James K., "Materialism through the eyes of Polish and American consumers," J Bus Res, vol. 64, no. 9, pp. 944-950, [Online] Available: http://dx.doi.org/10.1016/j.jbusres.2010.11.016, 2011.

[24] Kaylani, "Dating Someone with a Hedonistic lifestyle," Futurescopes. Retrieved from: http://futurescopes.com/dating/specialized-dating/2614/dating-someone-hedonistic-lifestyle, 2019.

[25] AEST, "What is hedonism and how does it affect your health?," The Conversation, Retrieved from: http://theconversation.com/what-is-hedonism-and-how-does-it-affect-your-health-78040,2017.

[26] Policardo L, Carrera EJS, "Corruption causes inequality, or is it the other way around? An empirical investigation for a panel of countries," Economic Analysis and Policy, vol. 59, pp. 92-102, 2018.

[27] David G. Allan, C. "The meaning(s) of (your) life," CNN, [Online] Available: https://edition.cnn.com/2018/01/31/health/meaning-of-life-wisdom project/index.html, 2019.

[28] Hunainah, Arum D. R. English Translation of The Qur'an 28:49-50, Bekasi: Cipta Bagus Segara, 2012.

[29] Trigunayat, U. "Philosophy: What is the opposite of materialism?," Quora.com, [Online] Available: https://www.quora.com/Philosophy-What-is-the-opposite-of-materialism, 2019.

[30] Emerson R. W., Wise Old Sayings, Retrieved from Wise Old Sayings.

[31] Christopher AN, Kuo SV, Abraham KM, Noel LW, Linz HE., "Materialism and affective well-being: The role of social support," Personality and Individual Differences, vol. 37, no. 3, pp. 463-470, 2004.

[32] Arndt J, Solomon S, T. "The Urge to Splurge: A Terror Management Account of Materialism and Consumer Behavior," Journal of Consumer Psychology, vol. 14, no. 3, pp. 198-212, 2004.

[33] Seenshopi.com, "What Is the Purpose of Life? 7 Signs You're Not Living It," Retrieved from: https://sensophy.com/what-is-the-purpose-of-life-or-meaning-of-life/_2017. 